\title{
Validation of the Airways Questionnaire 20 - AQ20 in patients with chronic obstructive pulmonary disease (COPD) in Brazil*
}

\author{
AQUILES CAMELIER ${ }^{1}$, FERNANDA ROSA ${ }^{2}$, PAUL JONES ${ }^{3}$, JOSÉ ROBERTO JARDIM ${ }^{4}$
}

\begin{abstract}
Introduction: A great emphasis has been placed on health-related quality of life of COPD patients and specific questionnaires have been developed in order to measure it. Objective: This study describes the language and cultural adaptation of a new (and short) disease-specific health status questionnaire developed for chronic obstructive pulmonary diseases: the Airways Questionnaire 20 (AQ20). Methods: In order to validate this questionnaire in Brazil, it was initially translated into Portuguese. The cultural adaptation was taken into consideration and then a back translation to English was undertaken, in order to obtain a final Portuguese version. Correlations were made with FEV,$S_{2} O_{2}$, BMI and another diseasespecific health status questionnaire, the Saint George Respiratory Questionnaire (SGRQ), previously validated in Brazil. The interclass correlation ratio was done to test the reproducibility of AQ20. Results: The interclass correlation ratio for the total score was $\alpha=0.90$ (intra-observer variability) and $\alpha=0.93$ (inter-observer variability) ( $p<0.05$ for both). The correlation with total SGRQ score was 0.76, with $p<0.001$. The average time to answer the AQ20 was 4 min and 6 s.

Conclusion: The Brazilian Portuguese version of AQ20 is reproducible, of fast application and with good a correlation with SGRQ total score, which makes it a valid questionnaire to measure health status in obstructive patients in Brazil. (J

Pneumol. 2003; 29(1): 28-35)
\end{abstract}

Key words - Obstructive lung diseases. Questionnaire. Quality of life. Reproducibility of results.

\footnotetext{
Abbreviations used in this study

AQ20 - Airways Questionnaire 20

SGRQ - Saint George Respiratory Questionnaire

CRQ - Chronic Respiratory Questionnaire

SF36 - Short Form 36

AQLQ - Asthma Quality of Life Questionnaire
}

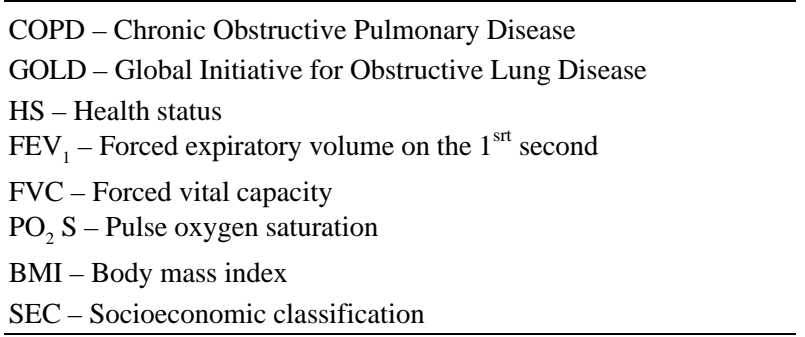

* Work carried out in the Department of Pneumology of the Pulmonary Rehabilitation Center of Universidade Federal de São Paulo (UNIFESP), São Paulo, SP. Financial support from CAPES. This material is partially composed by the first author's Master Thesis.

1. Master in Pneumology. Assistant Physician of Pneumology. Vice-Director of the Pulmonary Rehabilitation Center. Expert title from SBPT.

2. Expert in Respiratory Physiotherapy. Coordinator of the Pulmonary Rehabilitation Center.

3. Professor, Respiratory Medicine. St. George's Hospital Medical School, London, UK.

4. Associate Professor of Pneumology. Director of the Pulmonary Rehabilitation Center.

Mailing address - Aquiles Camelier, Disciplina de Pneumologia, Universidade Federal de São Paulo (UNIFESP) - Escola Paulista de Medicina (EPM), Rua Botucatu, 740, $3^{\circ}$ andar - 04023-062 - São Paulo, SP. Phones.: (55-11) 5576-4238/5572-4301; e-mail: aquilescamelier @ hotmail.com; josejardim@pneumo.epm.br

Received for publication in 5/21/02. Approved, after revision, in 11/6/02.

\section{INTRODUCTION}


The emphasis on the treatment of COPD patients has been directed at reduction of symptoms, increased physical tolerance and improvement of health-related quality of life, also named health status (HS $)^{(1-3)}$. Several worldwide studies have incorporated HS measurement as a parameter to evaluate the efficacy of several interventions ${ }^{(4-8)}$. However, to measure HS in languages and cultures different from the original one, it is recommended that these instruments undergo a validation process ${ }^{(9,10)}$. Of the HS questionnaires used in COPD, two were already validated in Brazil: the SF-36 ${ }^{(11)}$ and the SGRQ $^{(12,13)}$. The length of the questionnaire may be important ${ }^{(14)}$ and, in 1994, short 20-item questionnaire was composed, called Airways Questionnaire 20 - AQ20, with validity and reproducibility demonstrated in the literature ${ }^{(15,16)}$. AQ20 has similar discriminative and responsivity properties when compared to SGRQ $\left(r=0.86\right.$ in $\left.\operatorname{COPD}^{(17)}\right)$ and to the Asthma Quality of Life Questionnaire (AQLQ); $r=0.80^{(16)}$.

The present study describes the adaptation to the Brazilian language and culture of a new (and short) questionnaire of disease-specific health status developed for chronic obstructive respiratory diseases: the Airways Questionnaire 20 - AQ20.

\section{MATERIAL AND METHODS}

A) Sample: The AQ20 was applied to 30 patients, selected from the COPD Ambulatory of Pneumology/UNIFESP.

B) Inclusion criteria: I - COPD diagnosis: established according to the criteria of GOLD consensus ${ }^{(1)}$; II - Clinical stability, before and after the study, according to the criteria established in a previous study ${ }^{(12)}$.

C) Exclusion criteria: I - Presence of pulmonary diseases other than COPD; II - Presence of other non-pulmonary diseases considered incapacitating, severe or of difficult control and III - Patient's request and/or non-attendance to the programmed consultations;

D) Protocol: In a similar way, this study used in Brazil the phases described for validtion and cultural adaptation of the $\mathrm{SGRQ}^{(12)}$ and the SF-36 ${ }^{(11)}$, as well as the validation of the Swedish version ${ }^{(18)}$ and the Spanish version of the SGRQ ${ }^{(19)}$, in addition to other phases described in the International Quality of Life Assessment Project ${ }^{(20)}$.

D.1) Translation into Portuguese - language/cultural equivalence:

The questions of the original English version of the AQ20 were initially translated into Portuguese (the conceptual, rather than the literal translation, was emphasized), obtaining the first Portuguese version. This initial version was applied in 13 COPD patients enrolled in the Pulmonary Rehabilitation Program of UNIFESP, and possible text-related doubts and difficulties were investigated. The second Portuguese version was made after this initial assessment. Subsequently, a retrograde translation into English was performed by a Brazilian physician with a good knowledge of English, who, however, was not familiar with the AQ20. The two English versions (original and retrograde) were compared. Finally, a final version of the AQ20 in Portuguese was written (Appendix 1). No specific item in the cultural adaptation needed to be replaced.

D.2) Evaluation of reproducibility and validity of the AQ20:

The AQ20 was applied three times to the same patient, twice on the first day and a third one 15 days later. Only two experimenters participated in the application of the questionnaires. In the first consultation, AQ20 was applied twice in different moments, randomly (by raffle), by different experimenters (experimenter 1 and 2) who had no previous access to the answers of each application. This procedure was used to assess the inter-observer reproducibility. After a period of 15 days, AQ20 was again applied by experimenter 1, for the study of intra-observer reproducibility. AQ20 validity was evaluated by examination of its score relationship with that of SGRQ, FEV $1, \mathrm{FEV}_{1} / \mathrm{FVC}, \mathrm{SpO}_{2}(\%)$, BMI and SEC.

D.3) Assessment for AQ20 validation:

Spirometry, performed in a Vitatrace equipment - VT 130SL and previously described ${ }^{(21)}$; oxygen saturation $\left(\mathrm{SPO}_{2}\right)$, measured at rest (after 15 min seating) breathing environmental air with a Pulse oximeter Model 300 - Palco Laboratories; Questionnaire of Clinical Stability, standardized by UNIFESP/Pneumology ${ }^{(12)}$; BMI $\left(\mathrm{kg} / \mathrm{m}^{2}\right)$, where malnutrition was considered as below 22, eutrophism, between 22 and 27, and overweight, with a BMI above $27^{(22)}$ and SEC ${ }^{(23)}$, according to the Brazilian Society of Market Research.

D.4) Doubts: patients were requested to answer a standard questionnaire at the end of AQ20 application, in order to provide complementary information about the easiness and difficulties to answer the AQ20.

Patients signed a free informed consent form and the protocol was approved by the Ethics Committee in Medical Research of Hospital São Paulo/UNIFESP.

\begin{tabular}{|c|c|c|c|}
\hline \multicolumn{4}{|l|}{$\begin{array}{c}\text { APPENDIX 1 } \\
\text { Airway Questionnaire } 20 \text { (AQ20) }\end{array}$} \\
\hline $\begin{array}{l}\text { The following questions refer to the effect of the pulmonary disease in your daily life } \\
\text { Please, answer Yes, No or Does not apply for each item. Do not leave any blanks. }\end{array}$ & & & \\
\hline Question & Yes & No & Does \\
\hline
\end{tabular}




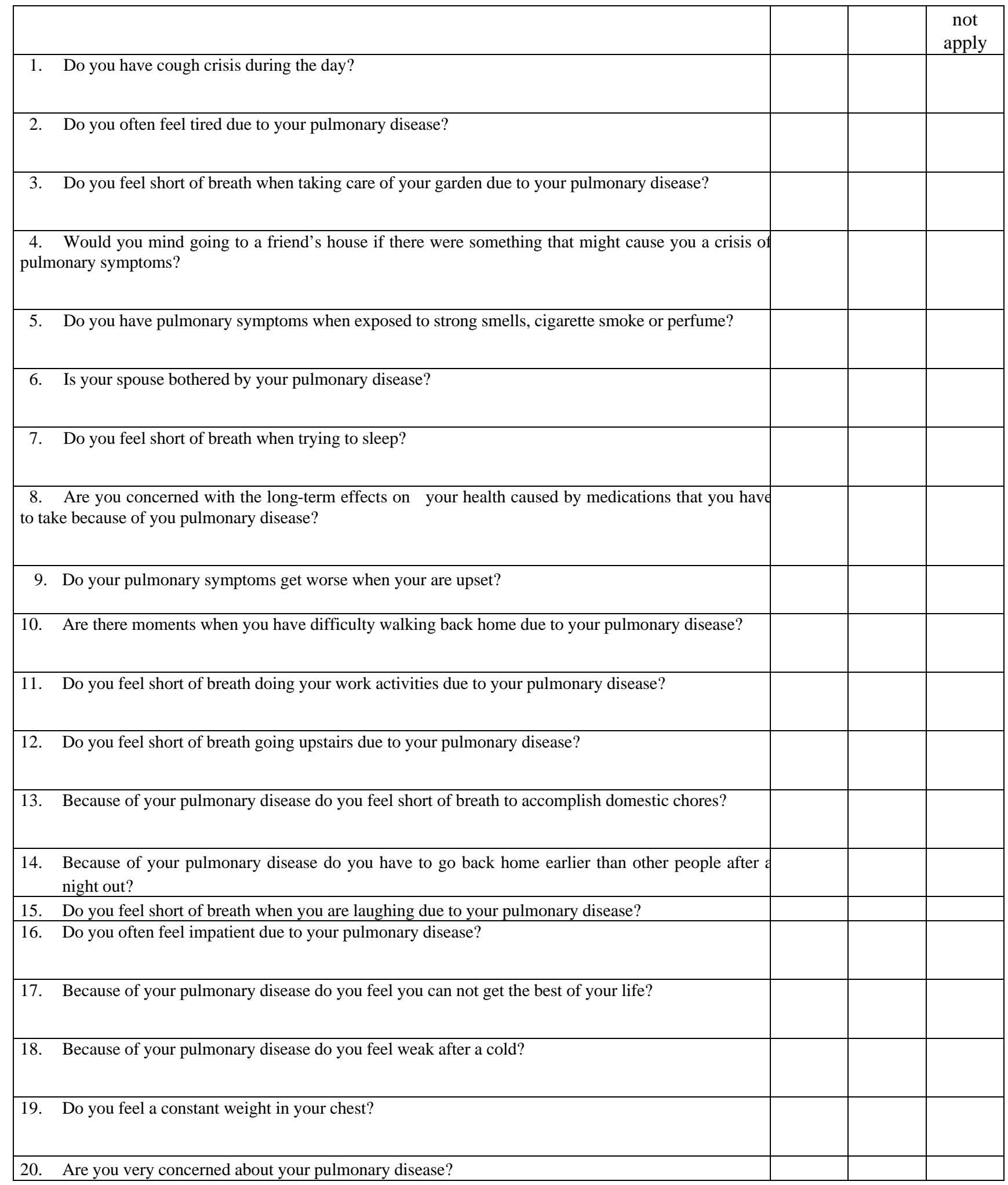

e) Statistical analysis: A descriptive statistical analysis was used for demographic and clinical characterization of the patients. The Pearson Chi-Square test was used to examine the relationship between two dichotomic variables. Comparison between two dependent samples was made by the Wilcoxon matched pairs test. Comparison of two independent samples was performed by the Mann-Whitney U Test. Cronbach's coefficient was used to assess AQ20 reproducibility. Correlation between two ordinal variables was carried out by the Spearman Correlation Coefficient. Since correlation coefficient 
evaluates the level of association between the score obtained in a test-retest situation, but does not indicate the direction of such association, the graphic disposition of Bland and Altman was used, since it examines the difference between scores obtained in the AQ20 and SGRQ. In this graphic disposition, the differences are placed, the general mean and variances are calculated, and a 95\% confidence interval around the mean is built, assuming a normal distribution ${ }^{(24,25)}$. The Kappa confidence coefficient was used to measure the level of concordance between two evaluations arranged by categories (nominal level). The level of significance was set at $\mathrm{p}<0.05$.

\section{RESULTS}

Thirty five patients were initially recruited; however, three of them presented clinical instability and two did not return for the second consultation, making up a total of 30 patients. The mean time of AQ20 application was four minutes, The main characteristics of the 30 patients who concluded the study are shown in Table 1.

Of the 30 patients, 25 were male $(83.3 \%)$, seven $(23.4 \%)$ were undernourished and $14(46.6 \%)$, obese; regarding their socioeconomic classification, two patients belonged to B1 class (6.7\%), four to the B2 class (13.3\%), 16 to class $\mathrm{C}$ (53.3\%) and eight, to class D (26.7\%). None of the patients belonged to class A. Seven patients $(23.3 \%)$ were illiterate and, in this case, the questionnaires were read aloud by the experimenter, rigorously following the author's instructions. There were no significant alterations of pulmonary function and $\mathrm{SPO}_{2}$ in the evaluation days (Table 2). Regarding the stage of the disease, four $(13.3 \%)$ were in stage I, $11(36.7 \%)$ in stage IIa, $10(33.3 \%)$ in stage IIb and five (16.7\%) in stage III, according to GOLD classification ${ }^{(1)}$. Five patients $(16.7 \%)$ were hypoxemic $\left(\mathrm{SpO}_{2} \leq 88 \%\right)$ and used continuous home oxygen therapy.

Intra-class correlation coefficient for analysis of intra-observer variability (total score with 15 days of interval) showed an $\alpha=0.90$. Inter-observed analysis of variability evaluated in the same day revealed an $\alpha=0.93$ and in different days the $\alpha=$ 0.92 ; all of these correlations were considered excellent ${ }^{(26)}$.

AQ20 score is obtained according to the type of answer chosen by the patient. The options allowed by the questionnaire are "Yes", "No", "Does not apply". For the study of intra-observer concordance (in different days) the Kappa was calculated individually for each question, and the values are listed in Table 3; for the intra-observed concordance (same day), data are shown in Table 4 (the answers "No" and "Does not apply" were considered as distinct, despite representing same score).

Other correlations were evaluated with measurements performed in the clinical practice, such as $\mathrm{FEV}_{1}(\%), \mathrm{FEV}_{1} / \mathrm{FVC}$, $\mathrm{SpO}_{2}$, BMI, education and SEC (Table 5).

Spearman correlation analyses of AQ20 and symptom, activities and impact domains of the SGRQ are presented in Table 6. The correlation between total score of the SGRQ and AQ20 was considered good $(r=0.76)$ as shown in Figure 1. Since AQ20 is not divided in domains, the result of its correlation with total score of SGRQ can be emphasized. For analysis of individual variability to compare the results of AQ20 x SGRQ (total \%), the Bland and Altman graphic arrangement was performed as shown in Figure 2.

Patients were distributed as severe $\left(\mathrm{FVE}_{1}<40 \%\right)$ and not severe $\left(\mathrm{FVE}_{1}>40\right)^{(27)}$, hypoxemic $\left(\mathrm{SpO}_{2} \leq 88 \%\right)$ and not hypoxemic, in order to study the changes of correlations of AQ20 and SGRQ. The data are presented in Table 7. 


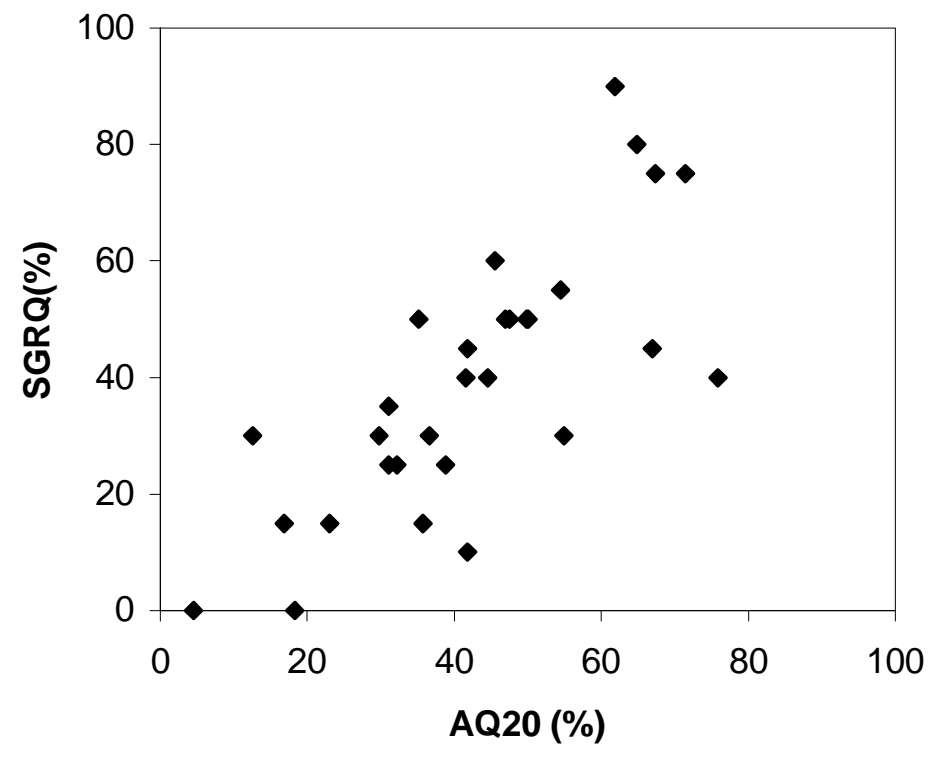

Figure 1 - Spearman correlation between total scores (\%) of the AQ20 and SGRQ

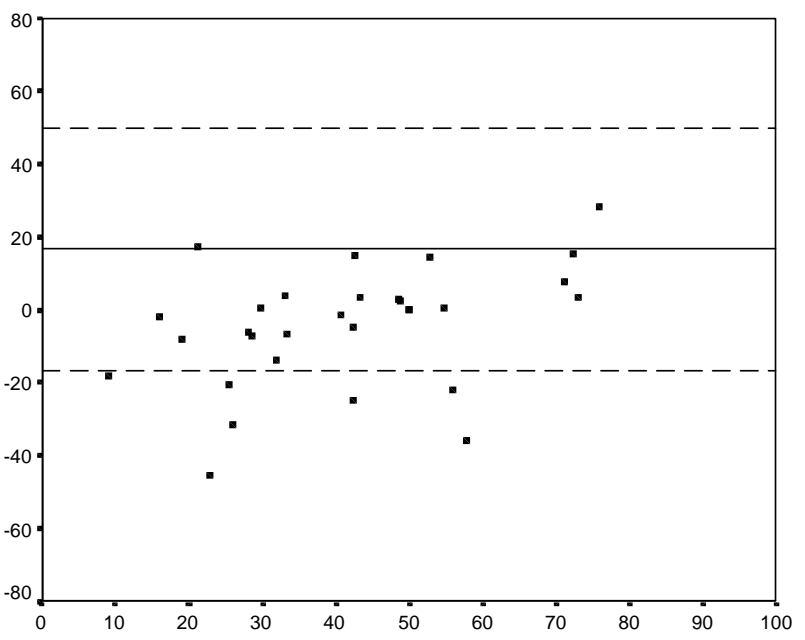

Figure 2 - Graphic arrangement (Bland and Altman) of the differences between AQ20 (\%) - SGRQ (total \%) versus the average scores.

\section{DOUBTS}

All 30 patients answered to some standard questions on possible doubts about the AQ20 at the time of the second consultation. Twenty five patients $(83.3 \%)$ considered the questionnaire of good size and 28 (93.3\%), easy to answer. Twenty six patients $(87.7 \%)$ did not have any doubt to answer the AQ20. The four questions that raised doubts were: 1) question 5: patient 5 wanted to have another alternative to answer, besides yes or no; 2) question 8: patient 7 initially did not understand the question statement; 3) question 18: patient 17 felt weak because of a diet; 4) question 6: patient 3 did not known his spouse's opinion. 
TABLE 1

$\mathrm{BMI}, \mathrm{FEV}_{1}, \mathrm{FEV}_{1} / \mathrm{FVC}$ (absolute) and $\mathrm{SpO}_{2}$ values of 30 patients who answered to the Airway Questionnaire 20 (AQ20) twice

\begin{tabular}{lccc}
\hline & Mean & Median & $\begin{array}{c}\text { Standard } \\
\text { deviation }\end{array}$ \\
\hline Age (years) & 8.6 & 68.5 & 8.5 \\
$\mathrm{BMI}_{\mathrm{FEV}}$ (L) & 25.7 & 26.3 & 4.7 \\
$\mathrm{FEV}_{1}(5)$ & 1.26 & 1.10 & 0.50 \\
$\mathrm{FEV}_{1} / \mathrm{FVC}$ & 56.8 & 50.2 & 23.3 \\
$\mathrm{SpO}_{2}(\%)$ & 47.1 & 46.1 & 11.0 \\
\hline
\end{tabular}

TABLE 2

$\mathrm{FEV}_{1}, \mathrm{FEV}_{1} / \mathrm{FVC}$ and $\mathrm{SpO}_{2}$ values of 30 patients who answered to the AQ20 twice within 15 days interval

\begin{tabular}{lccccccc}
\hline & \multicolumn{2}{c}{ Mean } & \multicolumn{2}{c}{ Median } & \multicolumn{2}{c}{ Standard deviation } & $\mathbf{p}$ \\
\hline & $\mathbf{1}^{\text {rst }}$ day & $\mathbf{2}^{\text {nd }}$ day & $\mathbf{1}^{\text {rst }}$ day & $\mathbf{2}^{\text {nd }}$ day & $\mathbf{1}^{\text {rst }}$ day & $\mathbf{2}^{\text {nd }}$ day & \\
$\mathrm{FEV}_{1}(\mathrm{~L})$ & 1.26 & 1.25 & 1.10 & 1.07 & 0.50 & 0.48 & 0.91 \\
$\mathrm{FEV}_{1}(\%)$ & 56.8 & 56.8 & 50.2 & 49.7 & 23.3 & 22.3 & 0.97 \\
$\mathrm{FEV}_{1} / \mathrm{FVC}$ & 47.1 & 47.3 & 46.1 & 47.8 & 11.0 & 11.1 & 0.68 \\
$\mathrm{SpO}_{2}$ & 92.3 & 92.1 & 93.0 & 93.0 & 3.5 & 3.0 & 0.51 \\
\hline
\end{tabular}

TABLE 3

Kappa and $p$ values calculated for each answer of the $1^{\text {rst }}$ AQ20 questions compared with those of the $3^{\text {rd }}$ AQ20

\begin{tabular}{lcc}
\multicolumn{2}{c}{ AQ20 questions compared with those of the $\mathbf{3}^{\text {rd }} \mathbf{A Q 2 0}$} \\
\hline & Kappa value & $\mathbf{P}$ \\
\hline Question 1 & 0.201 & 0.27 \\
Question 2 & 0.336 & 0.06 \\
Question 3 & 0.645 & $<0.01$ \\
Question 4 & 0.248 & 0.06 \\
Question 5 & 0.597 & $<0.01$ \\
Question 6 & 0.501 & $<0.01$ \\
Question 7 & 0.493 & $<0.01$ \\
Question 8 & 0.132 & 0.21 \\
Question 9 & 0.524 & $<0.01$ \\
Question 10 & 0.667 & $<0.01$ \\
Question 11 & $<0.01$ \\
Question 12 & 0.361 & 0.02 \\
Question 13 & 0.429 & $<0.01$ \\
Question 14 & 0.659 & 0.04 \\
Question 15 & 0.243 & $<0.01$ \\
Question 16 & 0.400 & 0.10 \\
Question 17 & 0.286 & $<0.01$ \\
Question 18 & 0.526 & $<0.01$ \\
Question 19 & 0.560 & 0.20 \\
Question 20 & 0.147 & $<0.01$ \\
\hline
\end{tabular}


TABLE 4

Kappa and $p$ values calculated for each answer of questions from the $1^{\text {rst }}$ $\mathbf{A Q 2 0}$ versus the $2^{\text {nd }} \mathbf{A Q 2 0}$ (inter-observer concordance in the same day)

\begin{tabular}{lcc}
\hline & Kappa value & P \\
\hline Question 1 & 0.661 & $<0.01$ \\
Question 2 & 0.537 & $<0.01$ \\
Question 3 & 0.600 & $<0.01$ \\
Question 4 & 0.664 & $<0.01$ \\
Question 5 & 0.578 & $<0.01$ \\
Question 6 & 0.524 & $<0.01$ \\
Question 7 & 0.783 & $<0.01$ \\
Question 8 & 0.460 & $<0.01$ \\
Question 9 & 0.444 & $<0.01$ \\
Question 10 & 0.426 & $<0.01$ \\
Question 11 & $<0.01$ \\
Question 12 & 0.522 & $<0.01$ \\
Question 13 & 0.700 & $<0.01$ \\
Question 14 & 0.731 & $<0.01$ \\
Question 15 & 0.474 & $<0.01$ \\
Question 16 & 0.308 & $<0.01$ \\
Question 17 & 0.730 & $<0.01$ \\
Question 18 & 0.591 & $<0.01$ \\
Question 19 & 0.530 & $<0.01$ \\
Question 20 & 0.446 & $<0.01$ \\
\hline
\end{tabular}

TABLE 5

Non-parametric correlation (Spearman) between total score and percentage of $A Q 20$ ( $A Q 20$ and $A Q 20 \%$, respectively) and $F E V_{1}$ (absolute and percentage values), $\mathrm{FEV}_{1} / \mathrm{FVC}, \mathrm{SpO}_{2}(\%)$ socioeconomic class (SEC), education and BMI

\begin{tabular}{|c|c|c|}
\hline & $1^{\text {rst }} A Q 20$ & $1^{\text {rtt }}$ AQ 20\% \\
\hline \multicolumn{3}{|l|}{$1^{\text {rtt }} \mathrm{FEV}_{1}(\%)$} \\
\hline Correlation coefficient & -0.216 & -0.216 \\
\hline $\mathrm{p}$ & 0.251 & 0.251 \\
\hline \multicolumn{3}{|l|}{$1^{\text {rt }} \mathrm{FEV}_{1} / \mathrm{FVC}$} \\
\hline Correlation coefficient & -0.108 & -0.108 \\
\hline$p$ & 0.569 & 0.569 \\
\hline \multicolumn{3}{|l|}{$1^{\text {rst }} \mathrm{SpO}_{2}(\%)$} \\
\hline Correlation coefficient & -0.069 & -0.069 \\
\hline $\mathrm{p}$ & 0.717 & 0.717 \\
\hline \multicolumn{3}{|l|}{ SEC } \\
\hline Correlation coefficient & -0.099 & -0.099 \\
\hline$p$ & 0.602 & 0.602 \\
\hline \multicolumn{3}{|l|}{ Education } \\
\hline Correlation coefficient & 0.038 & 0.038 \\
\hline$p$ & 0.841 & 0.841 \\
\hline \multicolumn{3}{|l|}{ BMI $\left(\mathrm{kg} / \mathrm{m}^{2}\right)$} \\
\hline Correlation coefficient & -0.159 & -0.159 \\
\hline$p$ & 0.401 & 0.401 \\
\hline
\end{tabular}


TABLE 6

Non-parametric correlation (Spearman) between AQ20

and the results of the three domains of the SGRQ

(symptoms, activities and impact) on the first application

\begin{tabular}{|c|c|}
\hline $1^{\text {rt }}$ SG RQ \% & $1^{\text {rst }}$ AQ 20\% \\
\hline $\begin{array}{c}\text { Symptoms } \\
\text { Correlation coefficient } \\
p\end{array}$ & $\begin{array}{l}0.40 \\
0.03\end{array}$ \\
\hline $\begin{array}{c}\text { Activities } \\
\text { Correlation coefficient } \\
p\end{array}$ & $\begin{array}{l}0.67 \\
<0.001\end{array}$ \\
\hline $\begin{array}{c}\text { Impact } \\
\text { Correlation coefficient } \\
p\end{array}$ & $\begin{array}{l}0.71 \\
<0.001\end{array}$ \\
\hline $\begin{array}{c}\text { Total } \\
\text { Correlation coefficient } \\
p\end{array}$ & $\begin{array}{l}0.76 \\
<0.001\end{array}$ \\
\hline
\end{tabular}

TABLE 7

Non-parametric correlation (Spearman) between AQ20(\%) and the SGRQ results (total \%) of the non-severe $\left(\right.$ FEV $\left._{1} \geq 40\right)$, severe $\left(\mathrm{FEV}_{1}<40\right)$, non-hypoxemic $\left(\mathrm{SpO}_{2} \leq 88 \%\right)$ and hypoxemic $\left(\mathrm{SpO}_{2}>88 \%\right)$ patients

\begin{tabular}{|c|c|}
\hline $\mathbf{1}^{\text {rst }}$ SG RQ \% & $1^{\text {rst }}$ AQ 20\% \\
\hline \multicolumn{2}{|l|}{ Non severe } \\
\hline Coefficient correlation & 0.72 \\
\hline$p$ & $<0.01$ \\
\hline \multicolumn{2}{|l|}{ Severe } \\
\hline Coefficient correlation & 0.93 \\
\hline$p$ & $<0.01$ \\
\hline \multicolumn{2}{|l|}{ Non-hypoxemic } \\
\hline Coefficient correlation & 0.77 \\
\hline$p$ & $<0.01$ \\
\hline \multicolumn{2}{|l|}{ Hypoxemic } \\
\hline Coefficient correlation & 0.77 \\
\hline$p$ & $<0.001$ \\
\hline
\end{tabular}

\section{DISCUSSION}

AQ20 is a questionnaire of HS specific for obstructive respiratory diseases, with only three reports of its use in the literature until then ${ }^{(15-17)}$. Its great advantage is the shorter time of application with maintenance of measurement's properties. In order for a new test or instrument to be considered appropriate for the scientific community, the items are usually evaluated are reproducibility and its correlation with measurements traditionally used ${ }^{(28)}$. During the study of reproducibility intra- and inter-observed, the intra-class correlation (Cronbach) was calculated and an excellent concordance was observed when the application was made by the same person or by different experimenters. The minimum acceptable value to demonstrate reproducibility of a new instrument is an intra-class correlation coefficient equal or higher than 0.70 for a new questionnaire and higher than 0.80 for an old questionnaire ${ }^{(29)}$. In the present study the coefficients found were equal or higher than 0.90 . In the individual analysis of the answers obtained by the same experimenter on different days, a statistically significant concordance was observed in 14 of 20 questions of the AQ20 (Kappa confidence correlation). For different experimenters and questionnaire application on the same day, a significant concordance was found for all AQ20 questions. The difference between intra- and inter-observer did not influence the total score of the questionnaire, according 
to the results of the correlation coefficients described for both situations. This variation could be accounted for by application on different days, when factors such as anxiety and depression could influence $\mathrm{HS}^{(30)}$. Nonetheless, the hypothesis of an important individual variability of questionnaires and scales in general ${ }^{(31)}$ can not be excluded.

Comparisons with total score and domains of the SGRQ, a questionnaire widely used in the literature ${ }^{(4,32-34)}$ and validated in Brazil, was used to test the validation of AQ20, and a correlation coefficient ( $r$ ) of 0.76 ( $p<0.01$ ) for total score was found. These results are in accordance with two reports in the literature $(r=0.80 \text { and } r=0.86)^{(16,17)}$. In the comparative analysis between these two questionnaires, according to the graphic arrangement of Bland and Altman, a tendency of underestimation of the measurements of health status by the AQ20 was obtained, when compared to the SGRQ. This characteristic may be related to the small number of questions of AQ20. After a sample distribution according to the level of airflow limitation, excellent correlation was found for severe patients $(r=0.93)$ and moderate correlation $(r=0.72)$ for nonsevere patients. The difference of correlation between both group observed in this study may reflect a loss of sensibility of the AQ20 for measurement of health status in non-severe patients ${ }^{(17)}$, although the present study was not designed to assess this aspect. In regard to the level of $\mathrm{SpO}_{2}$ at rest, the correlation of AQ20 x SGRQ for hypoxemic and non-hypoxemic were similar ( $r=0.78$ for hypoxemic and $r=0.77$ for non-hypoxemic), therefore AQ20 demonstrated a good correlation with a traditional measurement of health status.

The main factors that influenced COPD patient's health status are dyspnea and psychological status, whereas the physiological parameters such as exercise capacity and $\mathrm{FEV}_{1}$ usually do not contribute so much to justify the alterations of this measurement ${ }^{(30)}$. To define the characteristics of a new instrument, however, it is necessary to know the correlations with routine measurements of clinical assessment. Therefore, correlations between AQ20 and $\mathrm{FEV}_{1}, \mathrm{FEV}_{1} / \mathrm{FVC}, \mathrm{SpO} \mathrm{P}_{2}, \mathrm{BMI}$ and SEC were made. None of these variables showed a significant correlation with AQ20 score when analyzed for the sample as a whole. Up to the present date, the only study in the literature which evaluated the correlation between AQ20

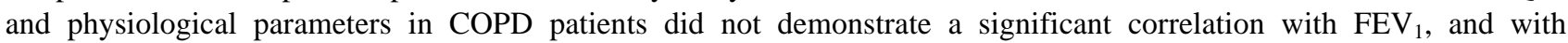
hyperinsufflation (ratio residual volume/total pulmonary capacity, measured with pletismography) ${ }^{(17)}$. For asthma patients there is a significant correlation with AQ20 for values in the peak of expiratory flow $(r=0.30$ when measured in the morning and $r=0.29$, at night), but no statistical difference was found for $\mathrm{FEV}_{1}{ }^{(16)}$.

One of the advantages of AQ20 mentioned in the literature is the time spent to apply it and, in the present study, the average was approximately four minutes, which is an advantage over CRQ and SGRQ.

In summary, we can conclude that AQ20 is a reproducible questionnaire, of fast application, with a good correlation with SGRQ, and which can be used to evaluate the health status of patients with obstructive disease in Brazil, especially in situations when time available for analysis of quality of life is short. As a basis for future studies, this group suggests a research for normal values of AQ20, as well as the definition of clinically relevant minimum differences, aspects that are extremely important to support its routine use.

\section{REFERENCES}

1. Pauwels RA, Buist AS, Calverley PMA, Jenkins CR, Hurd SS. Global initiative for chronic obstructive lung disease (GOLD) workshop summary. Am J Respir Crit Care Med 2001;163:1256-76.

2. Christopher JL, Murray, Alan DL. Evidence-based health policy - lessons from the Global Burden of Disease Study. Science 1996;274: 7403.

3. The Lung Health Study Research Group. Effect of inhaled triamcinolone on the decline in pulmonary function in COPD. N Engl J Med 2000; 343:1902-9.

4. Jones PW, Bosh TK. Quality of life changes in COPD patients treated with salmeterol. Am J Respir Crit Care Med 1997;155:1283-9.

5. Guyatt GH, King DR, Feeny DH. Generic and specific measurement of health-related quality of life in a clinical trial of respiratory rehabilitation. J Clin Epidemiol 1999;52:187-92.

6. Aaron SD, Vandemheen KL, Clinch JJ, Ahuja J, Brison RJ, Dickinson G, et al. Measurement of short-term changes in dyspnea and diseasespecific quality of life following an acute COPD exacerbation. Chest 2002;121:688-96.

7. Okubadejo AA, Jones PW, Wedzicha JA. Quality of life in patients with COPD and severe hypoxemia. Thorax 1996;51:44-7.

8. Jones P. Health status measurement in chronic obstructive pulmonary disease. Thorax 2001;56:880-7.

9. Guillemin F, Bombardier C, Beaton D. Cross-cultural adaptation of health-related quality of life measures: literature review and proposed guidelines. J Clin Epidemiol 1993;46:1417-32.

10. Guillemin F. Cross-cultural adaptation and validation of health status measures. Scand J Rheumatol 1995;24:61-3.

11. Ciconelli R, Ferraz M. Tradução para o português e validação do questionário genérico de avaliação de qualidade de vida "Medical Outcomes Study 36-Item Short Form Health Survey (SF-36)”. Rev Bras Reumatol 1999;39:143-50.

12. Souza TC, Jardim JRB, Jones P. Validação do questionário do Hospital Saint George na doença respiratória (SGRQ) em pacientes portadores de DPOC no Brasil. J Pneumol 2000;16:119-25.

13. Jones PW, Quirck FH, Baveystock CM. The St. George's respiratory questionnaire. Respir Med 1991;85 (Suppl B):25-31.

14. Quirk FH, Jones PW. Back to basics: how many items can adequately represent health-related quality of life in airways disease? Eur Respir Rev 1997;7:42,50-2.

15. Quirk FH, Jones PW. Repeatability of two new short airways questionnaires. Thorax 1994;49:1075-9. 
16. Barley EA, Quirk FH, Jones PW. Asthma health status measurement in clinical practice: validity of a new short and simple instrument. Respir Med 1998;92:1027-34.

17. Hajiro T, Nishimura K, Jones PW, Tsukino M, Ikeda A, Koyama H, et al. A novel, short, and simple questionnaire to measure health-related quality of life in patients with COPD. Am J Respir Crit Care Med 1999;159:1874-8.

18. Engstrom CP, Persson LO, Larsson S, Sullivan M. Reliability and validity of a Swedish version of the St. George's respiratory questionnaire. Eur Respir J 1998;11:61-6.

19. Ferrer M, Alonso J, Prieto L, Plaza V, Monsó E, Marrades R, et al. Validity and reliability of the St. George's respiratory questionnaire after adaptation to a different language and culture: the Spanish example. Eur Respir J 1996;9:1160-6.

20. Ware JE, Gandek B. International quality of life assessment (IQLA) project group: the SF-36 health survey. Int J Ment Health 1994;23:49-73.

21. I Consenso Brasileiro Sobre Espirometria. J Pneumol 1996;22:105-64.

22. Harmon-Weis S. Nutritional strategies and efficacious in the prevention/treatment of COPD. In: The role of nutrition in chronic disease care. Washington; 1999.

23. Sociedade Brasileira de Pesquisa de Mercado. Critério de classificação econômica Brasil. Boletim da Soc Bras Pesq Mercado 1997;2:31-2.

24. Brazier JE, Harper R, Jones NMB, O'Cathain A, Thomas KJ, Usherwood T, et al. Validating the SF-36 health survey questionnaire: the new outcome measure for primary care. BMJ 1992;305:160-4.

25. Bland JM, Altman DG. Comparing two methods of clinical measurement: a personal history. Int J Epidemiol 1995;24 (Suppl 1):S7-S14.

26. Levin J. Estatística aplicada a ciências humanas. 2a ed. São Paulo: Editora Harbra; 1987.

27. I Consenso Brasileiro de DPOC. J Pneumol 2000;26 (Supl 1):S1-S52.

28. Guyatt G, Walker S, Norman G. Measuring change over time: assessing the usefulness of evaluative instruments. J Chron Dis 1987;40: 1718.

29. Laureau S, Breslin EH, Meek PM. Functional status instruments: outcome measure in the evaluation of patients with chronic obstructive pulmonary disease. Heart Lung 1996;25:212-24.

30. Hajiro T, Nishimura K, Tsukino M. Comparison of discriminative properties among disease-specific questionnaires for measuring healthrelated quality of life in patients with COPD. Am J Respir Crit Care Med 1998;157:785-90.

31. Ciconelli RM. Tradução para o português e validação do questionário de qualidade de vida SF-36 (doutorado). São Paulo; Universidade Federal de São Paulo - Escola Paulista de Medicina; 1997.

32. Jenkinson C. Evaluating the efficacy of medical treatment possibilities and limitations. Soc Sci Med 1995;41:1395-401.

33. Shoup R, Dalsky G, Warner S. Body mass and quality of life in obstructive airway disease. Eur Respir J 1997;10:1578-80.

34. Ketelaars CAJ, Schlosser MAG, Mostert R. Determinants of health-related quality of life in patients with COPD. Thorax 1996;51:39-43. 